Discussion Paper No. 14-043

\title{
Determinants of Self-Reporting Under the European Corporate Leniency Program
}

Cung Truong Hoang, Kai Hüschelrath, Ulrich Laitenberger, and Florian Smuda

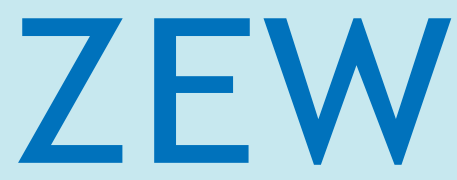

Zentrum für Europäische Wirtschaftsforschung $\mathrm{GmbH}$

Centre for European

Economic Research 
Discussion Paper No. 14-043

\title{
Determinants of Self-Reporting Under the European Corporate Leniency Program
}

\author{
Cung Truong Hoang, Kai Hüschelrath, \\ Ulrich Laitenberger, and Florian Smuda
}

Download this ZEW Discussion Paper from our ftp server:

http://ftp.zew.de/pub/zew-docs/dp/dp14043.pdf

Die Discussion Papers dienen einer möglichst schnellen Verbreitung von neueren Forschungsarbeiten des ZEW. Die Beiträge liegen in alleiniger Verantwortung der Autoren und stellen nicht notwendigerweise die Meinung des ZEW dar.

Discussion Papers are intended to make results of ZEW research promptly available to other economists in order to encourage discussion and suggestions for revisions. The authors are solely responsible for the contents which do not necessarily represent the opinion of the ZEW. 


\title{
DETERMINANTS OF SELF-REPORTING UNDER THE EUROPEAN CORPORATE LENIENCY PROGRAM
}

\author{
Cung Truong Hoang ${ }^{\circ}$, Kai Hüschelrath ${ }^{\star}$, \\ Ulrich Laitenberger* and Florian Smuda\#
}

July 2014

\begin{abstract}
We empirically investigate the determinants of self-reporting under the European corporate leniency program. Applying a data set consisting of 442 firm groups that participated in 76 cartels decided by the European Commission between 2000 and 2011, we find that the probability of a firm becoming the chief witness increases with its character as repeat offender, the size of the expected basic fine, the number of countries active in one group as well as the size of the firm's share in the cartelized market. Our results have important implications for an effective prosecution of anti-cartel law infringers.
\end{abstract}

Keywords Competition policy, cartels, leniency, European Union

JEL Class L41, K21

- Competition and Regulation Research Group, ZEW Centre for European Economic Research, P.O. Box 10 34 43, D-68034 Mannheim, Germany, E-mail: ct.hoang@aol.com.

* Competition and Regulation Research Group, ZEW Centre for European Economic Research, P.O. Box 10 34 43, D-68034 Mannheim, Germany, E-mail: hueschelrath@zew.de; MaCCI Mannheim Centre for Competition and Innovation; University of Mannheim, L7, 3-5, D-68131 Mannheim, Germany. Corresponding author. We are indebted to Eric Helland and an anonymous reviewer for valuable comments and suggestions on an earlier version of the paper. We are further grateful to Dominic Cucic, Amery Gülker, Bastian Sattelberger and Anne Zirngiebl for excellent research assistance. The usual disclaimer applies. Funding by the State of Baden-Württemberg as part of the Mannheim Centre for Competition and Innovation (MaCCI) and Strengthening Efficiency and Competitiveness in the European Knowledge Economies (SEEK) grants is gratefully acknowledged.

* Competition and Regulation Research Group, ZEW Centre for European Economic Research and MaCCI Mannheim Centre for Competition and Innovation, P.O. Box 1034 43, D-68034 Mannheim, Germany, Email: laitenberger@zew.de.

\# Competition and Regulation Research Group, ZEW Centre for European Economic Research and MaCCI Mannheim Centre for Competition and Innovation, P.O. Box 1034 43, D-68034 Mannheim, Germany, Email:smuda@zew.de. 


\section{Introduction}

The fight against hardcore cartels is ranked high on the agenda of competition authorities around the world. The recent efforts of, e.g., the European Commission (EC) to detect and subsequently punish cartels are reflected in an improved enforcement record. While the EC decided only 10 cartel cases in the 1995-1999 period, the number increased to 30 in the period from 2000-2004 and to 33 in the 2005-2009 period. ${ }^{1}$ Although this substantial increase is certainly driven by various policy changes such as new fining guidelines or an increased cooperation among competition authorities, many commentators argue that the introduction of the EC leniency program (LP) in 1996 is likely to be a key driver.

Generally, a LP offers law infringers (i.e., natural persons or firms) either a fine reduction of even full amnesty from fines if they disclose an infringement to the responsible authority and (fully) cooperate with it in the subsequent investigation. However, the design of leniency programs offers several degrees of freedom that may (directly or indirectly) influence the incentives of infringers to apply for leniency. Examples include the treatment of repeat offenders, the degree of fine reductions awarded to the first reporting infringer and the runnerup infringers, the treatment of ringleaders or the types of evidence that are considered sufficient to receive a reduction or even immunity from fines.

Against this background, we empirically investigate the determinants of self-reporting under the European corporate leniency program. Applying a data set consisting of 442 firm groups that participated in 76 cartels decided by the European Commission between 2000 and 2011, we find that the probability of a firm becoming the chief witness increases with its character as repeat offender, the size of the expected basic fine, the number of countries active in one group as well as the size of the firm's share in the cartelized market. Our results have important implications for an effective prosecution of anti-cartel law infringers.

The paper is structured as follows. The following Section 2 provides a review of the existing theoretical and empirical literature followed by a brief discussion of the determination of fines and the characteristics of the leniency program in the European Union in Section 3. Subsequently, Section 4 presents our empirical analysis. While Section 4.1 develops testable hypotheses, Section 4.2 describes the construction of the data set and discusses the descriptive statistics. Section 4.3 continues with the derivation of the econometric model and presents the key results of our empirical analysis. Section 4.4

1 Data source: European Commission (2013), Cartel Statistics (situation as of 5 December 2013), available at http://ec.europa.eu/competition/cartels/statistics/statistics.pdf . 
discusses these key results and derives both important policy conclusions and future research needs. Section 5 concludes the paper with a review of the key results.

\section{Review of the existing literature}

An empirical investigation of the determinants of becoming a chief witness can build on a rather rich theoretical and empirical literature. In the following, we restrict our review to the contributions that show a direct relation to our research question.

\subsection{Review of theoretical research}

In general, the life cycle of a cartel can be subdivided into three main stages: cartel formation, cartel stability and cartel breakdown. Following basic oligopoly theory, firms have an incentive to form a cartel because coordinating the respective competitive activities leads to greater profits than acting independently. The basic rationale for this allegation lies in the internalization of a negative externality. In a competitive market, a firm is simply interested in how much a reduction in its own output benefits itself, while it ignores the (positive) effect that a reduction in output has on the profits of the other firms in the market. A cartel internalizes this effect by taking into account how changes in the output level of each firm affect joint cartel profits. As a consequence, it pays for the cartel to reduce total output below the competitive level leading to increases in both market price and joint profits.

Closely related to the question why firms have incentives to form hardcore cartels is a large theoretical literature that investigates the determinants of cartel stability. In general, cartels typically face internal stability problems due to the short-run profit-driven incentives of individual members to deviate from the conspiracy. As a consequence, cartels have to implement monitoring and sanctioning mechanisms in order to stabilize their agreements. Ceteris paribus, such endeavors are more likely to be successful if the respective market is characterized by certain 'collusion-friendly' structural factors such as a high market concentration, a homogeneous product or a high market transparency (see, e.g., Motta (2004)).

Although many cartels have managed to operate successfully for decades or even centuries, observed breakdowns of cartels suggest that (changes of) internal and/or external factors can promote cartel instability and finally cause the collapse of the cartel. From a purely external perspective, cartels can break down because a competition authority detects the illegal conspiracy. Internally, however, cartels can become unstable and collapse because one or more individual cartel members come to the conclusion that their cost-benefit assessment has 
been altered in a way that suggests individual profits to be higher in a non-cartel state. Catalysts of such changes in individual cost-benefit assessments can be seen in, for example, market entry by non-cartel firms, technological changes (that might change various characteristics of the cartelized product), differences between current and future demand expectations (see, e.g., Rotemberg and Saloner (1986) or Haltiwanger and Harrington (1991)) or simply imperfect information between the firms in the cartel that might trigger price wars (see, e.g., Green and Porter (1984)).

Although cartels would also face the danger of breaking down in the absence of any kind of competition policy, it is undisputed that certain policy measures can have an impact on the collapse of cartels. For example, if the expected fines for cartelization are increased substantially, such a step would increase the costs of cartelization while leaving the benefits unchanged. As a consequence, ceteris paribus, some relatively unprofitable 'marginal' cartels are likely to break down and new cartels with comparable cost-benefit relationships are unlikely to be formed anymore.

The introduction and operation of a leniency program (LP) also aims at altering the costbenefit calculation of the cartel firms thereby making the collapse of a cartel more likely. In a seminal paper, Motta and Polo (2003) identify two diverging effects triggered by the introduction of a LP. On the one hand, firms are induced to come forward once an investigation is opened because the probability of being caught increases and the expected cartel profits decrease. Reporting reduces the expected fines and firms will therefore desist from continuing collusion. On the other hand, a LP might also give rise to an ex-ante procollusive effect, basically because the possibility of reporting and receiving immunity from fines reduces the expected costs of cartel detection and conviction.

In two further contributions, Spagnolo (2005) and Harrington (2008) describe the phenomenon that collusion might be destabilized because undercutting the agreed price - and consequently reporting - increases the payoff from cheating. However, on the contrary, LPs might also enhance collusion as reporting serves as a punishment strategy and therefore as a threat to fellow cartel members (see also Buccirossi and Spagnolo (2005)). If the threat is credible, firms will refrain from cheating and comply with the agreement. Complementary, Harrington (2008) describes the dominant strategy to report if the LP is more lenient and the expected payoff from continued collusion is therefore lowered. In case of symmetric information, all cartel members will prefer to report spurring a race to the competition authority's door. The effect is strengthened further with growing (expected) fine reductions between the first reporting firm and all subsequently reporting firms. 
In another model, Ellis and Wilson (2001) argue that LPs have asymmetric effects on firms thereby leading to different incentive to report an involvement in a cartel. Assuming that firms produce similar but differentiated goods, Ellis and Wilson (2001) identify additional gains from reporting (other than a fine reduction) as the first reporting firm can raise both its own marginal revenues - because the level of fines is set as a proportion of revenues - and the marginal costs of its rivals - because of costs for dealing with the competition authority or rebuilding reputation. As a consequence, the reporting firm improves its own market position relative to the position of the other firms operating in the market. ${ }^{2}$

In two very recent contributions by Harrington (2013) and Marvao (2013), a key assumption of previous leniency models is relaxed, namely symmetric information of all participating firms on the probability of detection and conviction (leading to symmetric equilibria in which either all firms apply for leniency or all firms stick to the cartel agreement). In real markets, however, it is reasonable to assume that firms have different expectations on the likelihood of getting caught which may result in some firms reporting the cartel while others do not. Against this background, Harrington (2013) models a two-firm cartel setting with firms having private information. He shows that a LP might motivate a firm not only to report the cartel because it fears detection by the competition authority but also because it fears to become the runner-up in the leniency race thereby missing out the chance to receive full amnesty.

Marvao (2013) aims at extending Harrington's model by allowing firms not only to have private information but also to be heterogeneous in terms of sales. Her setting is two-staged: in stage one, a cartel of two firms breaks down and in stage 2, firms decide whether or not to apply for leniency and report the cartel based on private signals of the expected probability of successful detection and conviction by the competition authority. Marvao (2013) shows that the firm chooses to report as soon as the value of reporting is higher than not reporting (which is a function of the rival's signal, its own signal and the expected fine) which in turn is dependent on the firm's sales level. In other words, the incentive to report is higher when the chances of getting caught and fined increase (as fines increase with the level of sales). As a consequence, lower reporting thresholds not only result from higher detection probabilities but also from individual firm characteristics - in this case the individual firm's level of sales.

Differences in terms of sales are often correlated with differences in firm size. However, alternative possibilities to measure firm size include the number of employees, whether the

2 However, again, cheating can also be used as a punishment strategy and threat to defecting cartel members thereby enhancing cartel stability. 
firm is publicly quoted, the size of market share or the number of markets in which the firm operates. Indeed, it is often reasonable to assume that firms may not operate only in one market but rather that they are diversified to a certain extent in terms of either product range and/or geographical expansion. In this respect, Motchenkova and van der Laan (2005) suggest an augmented incentive analysis of cartel members which - apart from expected fines and profit losses from the formerly cartelized product - also have to take sales reductions in other markets into account (due to reputational spillovers) in case they are found guilty of cartelization.

In a nutshell, existing theoretical research suggests that leniency programs can motivate individual cartel members to deviate from cartel agreements. Although there does not appear to be a fully developed theory of which cartel member is most likely to deviate from a cartel agreement (at what particular point in time) yet, key reasons include both the expectation to gain a competitive advantage compared to the other cartel members in the post-cartel world or simply to avoid a competitive disadvantage by becoming a cartel member that does not receive full leniency (and consequently have to pay large fines). In other words, LPs use the heterogeneity of cartel members (i.e. the different degrees of individual cartel profit) in combination with imperfect information to increase the probability to self-report thereby causing the collapse of the cartel.

\subsection{Review of empirical research}

Complementary to theoretical studies that aim at understanding the effects of leniency programs on cartel stability, the recent past has also seen substantial empirical research shedding light on this important research question. Although the majority of studies characterized in the following take the cartel as unit of observation, particularly two studies exist that base their empirical analyses on the individual (cartel) firm (or group) data.

A larger strand of empirical research investigates the lifespan of cartels in general and how exogenous shocks (such as policy changes) affect this lifespan in particular. Although the majority of these studies refer either to the United States (see, e.g., Levenstein and Suslow (2006)) or conduct comparisons between different jurisdictions (see, e.g., Abrantes-Metz et al. (2012)), De (2010) presents a cartel duration study solely for the European Union. Interestingly, she finds support for the hypothesis that changes in the EC policy regime, most notably the introduction of the LP, had a significantly positive effect on the (earlier) breakdown of existing cartels. Furthermore, her analysis also finds evidence consistent with 
the hypothesis that changes in either external market conditions or internal cartel organization structures had a significant impact on the average duration of cartels (in the EU).

In a more recent paper, Zhou (2012) also asks the question whether the introduction of the EC LP was successful in the sense that it decreased cartel stability thereby causing shorter cartel durations. Using a data set of all cartels convicted by the EC between 1985 and 2011, he is able to show that - consistent with his theoretical predictions - after the introduction of the most recent EC LP, cartel duration increased in the short-run suggesting that only 'marginal cartels' from a population of longer-lasting cartels are discovered immediately after the LP is introduced. In the long-run, however, he finds cartel duration to decrease below the short-run level basically because the LP imposes its full effect on cartels born after the policy change.

In another recent study, Gärtner and Zhou (2012) investigate the question whether LPs trigger 'a race to the enforcer's door' by testing whether leniency applications arise simultaneously with (or prior to) cartel breakdowns as well as the determinants of application delays. For the period from 1996 to 2012, they find that conspirators often apply for leniency long after a cartel collapses. Interestingly, their empirical analysis not only provides evidence that delays are symmetrically affected by competition policies and macroeconomic fluctuations but they also find support for the hypothesis that the revised LP of 2002 increased efficiency by shortening delays.

In another empirical study, Brenner (2009) investigates whether the introduction of the EC LP gives rise to increased information revelation by comparing cartels convicted before the introduction of the LP in 1996 to those convicted thereafter. He finds that (1) the EC obtained more evidence post-LP (with the amount of fine used as proxy) and the information provided was richer when leniency applicants and the EC cooperated more closely (with the amount of fine reduction due to leniency used as proxy); however, overall information revelation was found to have no impact on deterrence; (2) the level of cooperation had no significant effect on investigation and prosecution costs (with the duration of the investigation used as proxy); (3) the LP had no destabilizing effect on cartels (as measured by the number of years the cartel operated under the LP).

As mentioned in the beginning of this section, an empirical analysis of colluding firms (or groups of firms) instead of entire cartels has attracted much less attention in the empirical literature on leniency programs. To our knowledge, only two papers address questions similar 
to our study by using firm- and group-level data sets. In the first paper, Marvao (2013) ${ }^{3}$ uses a dataset comprising 81 cartels convicted by the EC between 1998 and 2011 and analyses the effect of firm-specific as well as cartel-specific variables on becoming the chief witness, the level of fines and a firm's turnover by using an OLS estimation method. She finds that the turnover of the first reporting firm after the investigation has started is higher than for the other cartel members; a result which confirms her preceding theoretical model. Furthermore, she finds that chief witnesses tend to participate in more than one cartel (with a larger number of members) and repeat offenders pay higher fines than first offenders.

In the second paper, Brenner (2011) also attempts to explain self-reporting behavior; however, with a particular focus on the organizational dimension. His econometric approach is sub-divided into two steps. In the first step, he uses variables on cartel-level only and indicates the propensity of a cartel given its characteristics to evoke self-reporting by a firm. In the second step, he switches to a firm-level perspective and integrates the propensity score into the second estimation by using a logit model. His results show that large, multinational and listed firms are more likely to become the chief witness. Brenner (2011) explains this observation with the advantages of large firms to deal with such legal challenges (both content-wise and financial budget-wise).

\section{Determination of fines and the leniency program in the European Union}

A prerequisite for an empirical examination of the determinants of self-reporting is an assessment of, first, the rules applied in the determination of fines, and second, the (potential) role of a leniency program (LP) in reducing these (expected) fines. As our empirical analysis below focuses on the European Union, we will concentrate our review of rules and regulations on this particular jurisdiction.

\subsection{Determination of fines}

By imposing fines, the European Commission basically pursues two interrelated goals: punishing detected breaches of competition law and deterring future infringements (see EC (2011)). Aiming at implementing both goals in an effective fashion, the EC introduced first 'Guidelines on the method of setting fines’ in 1998 (which were revised in 2006).

3 In a previous paper, Marvao (2010) applies a two-stage Heckman model in which she, firstly, estimates the probability that a cartel member receives leniency at all and, secondly, estimates the amount of reduction given the firm's cartel characteristics. She finds that the first reporting firm is very likely not only to receive leniency but also to get a higher fine reduction than the runner-up firms. 
The EC fine setting process begins with the derivation of a basic amount that essentially depends on (1) the firm's turnover, (2) the gravity and (3) the duration of the infringement. In an initial step, the EC determines the firm's turnover of the relevant product in the affected market generated in the last full business year preceding the end of the infringement (EC (2006)). The basic amount of the fine can reach up to 30 percent of these relevant sales depending further on, first, the gravity of the infringement (measured by factors such as the type of infringement, the combined market share and the geographic scope of the infringement). ${ }^{4}$ Second, the basic amount of the fine is directly influenced by the duration of the infringement. After fixing the appropriate percentage of the firm's cartel sales, the EC adds a duration multiplier, equal to the number of years in which the cartel was active. Furthermore, a so-called 'entry-fee' of 15 percent to 25 percent might be levied on top particularly for shorter cartels.

Subsequently, the EC might adjust the basic amount of the fine by taking account of socalled aggravating and mitigating circumstances. Factors that can lead to an increase in the fine include ringleader status or recidivism - i.e., for repeat offenders the fine can be increased by up to 100 percent for each prior infringement - while passive membership in the cartel or cooperation efforts (outside the leniency program) might reduce the basic amount of the fine.

In sum, the overall fine imposed must not exceed 10 percent of the firm's annual total turnover (EC (2006)). If the firm belongs to a group where the parent company exercised decisive influence over the operations of the subsidiary, the benchmark is the group's annual turnover instead of the individual firm's annual turnover. Furthermore, if the investigation started more than five years after the end of the infringement, no fine can be imposed (see EC (2011)). Further reductions (other than the leniency program) may be implemented if either the settlement procedure is applied (10 percent reduction, see EC (2008)) or in exceptional cases in which the firm proves its 'inability to pay' and the imposition of the full fine would seriously jeopardize the survival of the firm (see EC (2006)).

\subsection{The Leniency Program for cartel infringements}

A leniency program (LP) generally offers law infringers (i.e., natural persons or companies) either a fine reduction of even full amnesty if they disclose an infringement to the responsible authority and (fully) cooperate with it in the subsequent investigation. The degree of fine

4 Paragraph 23 of the Guidelines states that for horizontal price-fixing, market-sharing and output-limitation agreements, the proportion will be close to 30 percent (EC (2011)). However, in real cases, gravity is typically set between 15 percent and 20 percent. 
reduction typically depends on the point in time at which the infringer submits evidence (before or after the authority has started an investigation) and what kind of evidence is brought forward (i.e., how helpful the evidence is in proving the infringement).

In the EU, the first LP for cartel infringements was introduced in 1996 followed by two revisions in 2002 and 2006. The conditions for a leniency-related fine reduction or even amnesty were initially set out in the "Commission Notice on the non-imposition or reduction of fines in cartel cases” of 1996. The notice defined two different categories of fine reductions depending on the point in time at which the firm submits evidence to the EC. The 'Nonimposition of a fine or a very substantial reduction in its amount' (Section B) was possible if the firm 'informs the Commission about a secret cartel before the Commission has undertaken an investigation ... provided that it does not already have sufficient information to establish the existence of the alleged cartel' (para a). Furthermore, according to Section B (paragraphs b-e), the leniency applicant had to be the first to adduce decisive evidence of the cartel's existence (para b); it had to put an end to its involvement in the illegal activity no later than the time at which it discloses the cartel (para c); it had to provide the Commission with all the relevant information and all the documents and evidence available to it regarding the cartel and maintains continuous and complete cooperation throughout the investigation (para d); and it had not compelled another enterprise to take part in the cartel and has not acted as an instigator or played a determining role in the illegal activity (para e).

If all these criteria were met, the respective firm was awarded with a fine reduction between 75 percent and 100 percent. However, even if the criteria set out in para a were not fulfilled by the applicant, Sections C and D still defined possibilities for either a substantial or a significant reduction of the fine (50 percent to 75 percent or 10 percent to 50 percent, respectively).

Although the first EC leniency program already generated a significant number of cases of self-reporting, a lack of transparency was identified as key obstacle for further growth. In particular, even if a firm met all the requirements set out in section B (paras a to e), it still would have faced a substantial uncertainty whether it qualified for full immunity from fines. Furthermore, section B (para b) required the firm to 'adduce decisive evidence of the cartel's existence' without providing a clear idea what types (or degrees) of evidence were considered as 'decisive'.

With the first revision of the Notice in 2002, the EC aimed at improving the identified transparency problems and aimed at establishing 'a closer alignment between the level of reduction of fines and the value of a company's contribution' (EC (2002)). This is expressed 
clearly in the new section A (para 8) where the firm is required to be 'the first to submit evidence which [..] may enable [the Commission] to adopt a decision to carry out an investigation' or 'find an infringement [..] in connection with the alleged cartel' in order to receive full immunity with certainty. Applications that do not meet these high standards can still qualify for a reduction of 30 percent to 50 percent for the first runner-up, 20 percent to 30 percent for the second and up to 20 percent for all other firms if the reported evidence provides 'significant added value'.

In its second revision of the program in 2006, the EC on the one hand specified several procedures, most notably the rules for submission by introducing an explicit list of the evidence's content in the form of a corporate statement (EC (2002)). According to point A (para 9), the evidence is submitted in the form of a corporate statement that contains all relevant information on the clandestine agreement as well as details to all parties and individuals involved, along with other evidence that is related to the cartel. On the other hand, a marker system was introduced that basically aims at securing the correct place of the reporting firm in the order of all reporting cartel members.

\section{Empirical analysis}

In this section, we present our empirical analysis to assess the determinants of self-reporting under the EC corporate leniency program (LP), i.e., we provide answers to the question how chief witnesses differ from other cartel members. While Section 4.1 develops testable hypotheses, Section 4.2 describes the construction of the data set and discusses the descriptive statistics. Section 4.3 continues with the derivation of the econometric model and presents the key results of our empirical analysis. Section 4.4 discusses these key results and derives both important policy conclusions and future research needs.

\subsection{Hypotheses}

Our empirical analysis of the determinants of self-reporting is based on seven key hypotheses referring to (1) the duration of cartel participation, (2) repeat offender, (3) basic amount of fine, (4) undertaking based in the EEA, (5) number of countries within one undertaking, (6) number of firms within a group, and, last but not least, (7) market share.

\section{Duration of cartel participation}

As the expected fine for an individual firm increases proportionally with the duration of its participation in the cartel, the corresponding costs of collusion increase over time. Assuming 
that the benefits of collusion remain unchanged, self-reporting therefore can become the preferred option. Additionally, as all cartel members face higher fines over time, ceteris paribus, it becomes more attractive to apply for leniency to secure the first place in the leniency race to the enforcer's door (see Harrington (2013)).

H1: "The probability of being the chief witness increases with a cartel member's individual duration of cartel participation."

\section{Repeat offender}

In the EU, it is possible to impose a premium of up to 100 percent of the fine for each prior cartel infringement (see EC (2006)). Although in practice, no repeat offender was ever sentenced to pay a premium of more than 100 percent (even in the case of a firm that was involved in four prior cartels; see Veljanovski (2011)), it is still likely that the respective companies would face significant fine premiums thereby suggesting elevated incentives to self-report. Furthermore, repeat offenders are better informed about the procedures and consequences of a leniency application thereby lowering the threshold at which they decide to self-report. This increased incentive is likely to be fortified further by the revised LP of 2002 (that automatically guaranteed immunity from fines for the first reporting firm).

H2: "Repeat offenders are more likely to become the chief witness than single offenders. The probability is higher under the revised 2002 leniency program"

\section{Basic amount of fine}

Rational managers weigh profits and costs of reporting versus non-reporting. Ceteris paribus, higher fines increase the costs of cartelization thereby reducing its profitability and sustainability. A colluding firm can therefore be expected to regularly estimate the approximate level of fines without reporting making use of detailed information on how fines are calculated and how previous cartel members were fined. Although admittedly such an effect is likely to be stronger in jurisdictions that allow a punishment of the individual manager through pecuniary fines or even prison sentences (and not only stipulate punishing the firm as legal entity as in the EU), it can still be expected that being responsible for the construction of (or participation in) a cartel at least endangers the planned career paths of the respective managers (and that this effect is getting stronger with increasing fine levels). We therefore use the basic amount of the fine - as reported in the EC decisions - as proxy for a firm's expectations on the level of fines and expect that the probability of becoming the chief witness increases with the basic amount of the fine. 
H3: "The probability of becoming the chief witness increases with the basic amount of fine."

\section{Undertaking based in EEA}

Firms based in the EEA are likely to be better informed about the competition policy of the EC in general and the current policies and activities of cartel prosecutors in particular. As a consequence, they have better expectations on the likelihood of getting caught. It can further be expected that this effect is strengthened with the substantial 2002 revision of the LP. Although it reasonable to expect that firms react to such challenges in the form of changes in the cartel agreement and more extensive monitoring activities, it appears still likely that real markets with their uncertainties and incomplete information give rise to such geographical disparities.

H4: "A firm located in the EEA is more likely to become the chief witness. The probability further increases with the revised LP coming into force."

\section{Number of countries within one undertaking}

Ceteris paribus, multinationality (as measured by the number of countries involved within one group) increases the complexity of coordination. In addition to geographical distance, different cultural habits demand a more transparent business structure, favouring a higher probability to become the chief witness. Although it is again reasonable to expect that firms will anticipate such problems at the construction phase of the cartel, in real markets with many uncertainties and incomplete information, it appears likely that the involvement of more countries make the respective agreement and monitoring efforts more costly (and also more imperfect) thereby increasing the probability of a deviation of a cartel member. Furthermore, according to Motchenkova and van der Laan (2005), an undertaking consisting of firms operating in many countries (and markets) has to consider reputational spillover effects on sales after being detected as anti-cartel law infringer thereby triggering an increased probability to self-report.

H5: "The probability of being the chief witness increases with the number of countries within one group."

\section{Number of firms within a group}

The number of firms that form one undertaking can serve as an indicator of group size. Ceteris paribus, cartel-related coordination of large undertakings (involving many subsidiaries) is more difficult (compared to a smaller number of subsidiaries) basically 
because monitoring the respective agreements and implementing necessary responses to exogenous shocks requires more effort thereby leading to a higher probability to self-report.

H6: "The probability of being the chief witness increases with the number of firms that form one group."

\section{Market share}

A firm can improve its market position by cheating on its competitors (also participating in the cartel) thereby raising their costs (as they will be fined with certainty; see Ellis and Wilson (2001). Ceteris paribus, it can be expected that firms with higher market shares are more tempted to cheat through self-reporting, basically because these firms want to keep their dominant position in the market (and a high fine would jeopardize their own performance while strengthening the performance of the competitor who eventually receives immunity from fines).

H7: "The probability of being the chief witness increases with a firm's market share."

\subsection{Data and Descriptive Statistics}

The dataset applied in this paper contains information on all cartel cases decided by the European Commission between 2000 and 2011. The data were collected from decisions and press releases published by the EC in the course of its investigations and combine casespecific, group-specific as well as firm-specific information. Groups of firms were formed according to the respective EC decisions, i.e. firms within a group are linked through ownership and are jointly liable for cartel fines. ${ }^{5}$ On the case level, information such as cartel type, cartel duration, number of cartel members, affected industry, relevant geographic market(s) and imposed overall fines are available. Regarding firm- and group-specific data, we include information on the individual length of cartel participation, the level of fines imposed by the EC, whether the firm applied for leniency or not and the value of fine reductions following a successful leniency application. Furthermore, specific factors that are relevant for the calculation of the fine such as, e.g., aggravating and mitigating circumstances or repeat offenders are included. A detailed overview of the key variables used in our empirical analysis below is provided in Table 1.

5 As a consequence, leniency reductions are granted to the entire group. In order to keep one chief witness per cartel, we use an aggregated dataset with one observation corresponding to one group of firms. Firm-specific features are maintained by creating new aggregate variables. 
Table 1: List of variables

\begin{tabular}{|c|c|c|}
\hline Variable & Binary & Description \\
\hline \multicolumn{3}{|l|}{ GROUP VARIABLES } \\
\hline RELATIVE DURATION & No & Duration of group infringement relative to cartel duration, between 0 and 1 \\
\hline REPEAT OFFENDER & Yes & At least one repeat offender within group \\
\hline BASIC FINE & No & Basic fine for group, in million $€$, deflated with OECD CPI for Europe \\
\hline PREVIOUS FINE & No & Final previous fine for group (if repeat offender), in million $€$, deflated with CPI for Europe \\
\hline EEA & Yes & At least one firm within group located in EEA \\
\hline NO. COUNTRIES & No & Number of firm countries within group \\
\hline NO. FIRMS & No & Number of firms within group \\
\hline MARKET SHARE & No & Market share for cartel product and cartel market for group \\
\hline \multicolumn{3}{|c|}{ LENIENCY PROGRAM VARIABLES } \\
\hline LP 2002 & Yes & Leniency Notice of 2002 was applied \\
\hline \multicolumn{3}{|c|}{ CARTELCONTROL VARIABLES } \\
\hline DURATION & No & Duration of cartel, in months \\
\hline NO. FIRMS & No & Number of firms within cartel \\
\hline NO. GROUPS & No & Number of groups within cartel \\
\hline NO. COUNTRIES & No & Number of firm countries within cartel \\
\hline NO. REPEAT OFFENDERS & No & Number of repeat offenders within cartel \\
\hline
\end{tabular}

As shown in Table 1, we subdivide our key variables further into 7 'group variables', 1 'leniency program variable' and 5 'cartel control variables'. While group variables refer to a legally distinct cartel member (which often consists of more than one subsidiary firm), cartel control variables refer to the entire cartel (which by definition consists of at least two groups of undertakings). The binary 'leniency program variable' refers to the 2002 revision of the EC leniency program and allows us to investigate whether the revision generated measurable changes in self-reporting behavior.

Guided by the definition of the key variables, Table 2 below presents the descriptive statistics of our data set. In addition to the respective total values for the entire sample we also provide a split of the data set into 'chief witnesses' and 'other cartel members'. This split allows us to discuss some first descriptive evidence on the question whether and how the two groups differ. 
Table 2: Descriptive statistics

\begin{tabular}{|c|c|c|c|c|c|c|c|c|c|c|c|c|c|}
\hline & \multicolumn{4}{|c|}{ Chief witnesses } & \multicolumn{4}{|c|}{ Other cartel members } & \multicolumn{5}{|c|}{ Total } \\
\hline & i & $\mathrm{N}$ & Mean & Sd & ! & $\mathrm{N}$ & mean & Sd & $\mathrm{N}$ & Mean & Sd & $\min$ & Max \\
\hline DURATION & ! & 48 & 97.15 & 82.47 & i & 410 & 88.41 & 65.36 & 458 & 89.33 & 67.31 & 3 & 419 \\
\hline $\begin{array}{l}\text { RELATIVE } \\
\text { DURATION }\end{array}$ & $\begin{array}{l}1 \\
1 \\
1\end{array}$ & 48 & 0.89 & 0.25 & ' & 412 & 0.86 & 0.25 & 460 & 0.86 & 0.25 & 0.02 & 1 \\
\hline BASIC FINE & ! & 44 & 102.54 & 140.68 & : & 379 & 49.95 & 92.92 & 423 & 55.42 & 100.0 & 0.001 & 644.67 \\
\hline \multicolumn{9}{|c|}{--------4} & \multicolumn{5}{|c|}{ 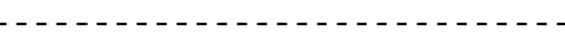 } \\
\hline $\begin{array}{l}\text { REPEAT } \\
\text { OFFENDER }\end{array}$ & : & 48 & 0.17 & 0.38 & $\vdots$ & 412 & 0.09 & 0.29 & 460 & 0.1 & 0.3 & 0 & 1 \\
\hline PREVIOUS FINE & i & 48 & 4.01 & 15.76 & i & 412 & 0.93 & 7.26 & 460 & 1.25 & 8.58 & 0 & 118.13 \\
\hline RINGLEADER & : & 48 & 0 & 0 & : & 412 & 0.06 & 0.23 & 460 & 0.05 & 0.22 & 0 & 1 \\
\hline$E E A$ & ; & 48 & 0.81 & 0.39 & , & 412 & 0.85 & 0.36 & 460 & 0.84 & 0.36 & 0 & 1 \\
\hline NO. COUNTRIES & : & 48 & 1.79 & 1.2 & ! & 412 & 1.45 & 0.88 & 460 & 1.49 & 0.92 & 1 & 8 \\
\hline NO. FIRMS & i & 48 & 2.25 & 1.86 & i & 412 & 1.88 & 1.36 & 460 & 1.92 & 1.42 & 1 & 12 \\
\hline MARKET SHARE & : & 34 & 0.25 & 0.16 & - & 245 & 0.15 & 0.13 & 279 & 0.17 & 0.14 & 0.002 & 0.91 \\
\hline \multicolumn{5}{|c|}{ 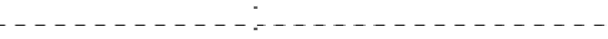 } & $\therefore$ & $-\ldots$ & --- & $\ldots$ & \multicolumn{5}{|c|}{----------------------} \\
\hline LP 1996 & : & 48 & 0.35 & 0.48 & 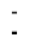 & 412 & 0.49 & 0.5 & 460 & 0.48 & 0.5 & 0 & 1 \\
\hline LP 2002 & I & 48 & 0.56 & 0.5 & ! & 412 & 0.48 & 0.5 & 460 & 0.48 & 0.5 & 0 & 1 \\
\hline LP 2006 & ! & 48 & 0.08 & 0.28 & i & 412 & 0.03 & 0.18 & 460 & 0.04 & 0.19 & 0 & 1 \\
\hline
\end{tabular}

In sum, our data set covers 460 groups that participated in 80 cartels detected between 2000 and 2011 (in which the leniency program was applied). Although we observe most variables for all groups in our data set, the two major exceptions are the 'basic amount of fine' and especially the 'market share' variable. In both cases, missing information in the respective EC decisions foreclosed the inclusion of the respective information for the missing groups.

Turning to a brief discussion of the values of the variables reported in Table 2, the average duration of cartel participation is found to be higher for chief witnesses (97 months) compared to the other cartel members (88 months). Furthermore, the average basic fine is substantially higher for the group of chief witnesses (EUR 103m) compared to the group of other cartel members (EUR 50m). The same general conclusion holds for the previous fine (that only applies in cases in which the respective group was a repeat offender) showing an average value of EUR 4m for the group of chief witnesses compared to a bit less than EUR $1 \mathrm{~m}$ for the other cartel members. Additionally, we find a higher proportion of 17 percent of repeat offenders among chief witnesses compared to only 9 percent among all other cartel members. Interestingly, we further find zero ringleaders among chief witnesses compared to 6 percent among the other cartel members. Although the 1996 Leniency Notice explicitly excluded 
ringleaders from full immunity, the 2002 revision relaxed this restriction. However, we still do not find evidence that former ringleaders ever became the chief witness. ${ }^{6}$

In terms of geographical characteristics the descriptive evidence does not show larger differences between chief witnesses and other cartel members. However, chief witnesses are found to stem from larger groups than the other cartel members. Also, chief witnesses on average have higher market shares (25\%) in the cartel market than other cartel members (15\%). Last but not least, in our sample, 56 percent of the chief witnesses fell under the 2002 LP compared to 35 percent referring to the $1996 \mathrm{LP}$ and the remaining 8 percent falling under the 2006 revision of the LP. Due to the small number of cases available for the 2006 revision of the LP, we will exclude the respective 4 cases and 18 groups from our empirical analysis below and therefore end up with 76 cartels and 442 groups in our data set.

\subsection{Econometric model and results}

In this section, we specify the econometric model and present our estimation results. As our outcome variable of interest is binary - which has a value of 1 if the infringing group is the chief witness and 0 otherwise - we estimate a probit model of the following form:

$$
\begin{aligned}
Y_{i}=F\left(y_{i}^{*}\right)= & F\left(\beta_{0}+\beta_{1} R E L \_D U R_{i}+\beta_{2} \text { BASIC_FINE }_{i}+\beta_{3} R E P \_O F F_{i}+\beta_{4} E E A_{i}\right. \\
& +\beta_{5} N O \_C O_{i}+\beta_{6} N O \_F I R M S_{i}+\beta_{7} M S H A R E \_M A X_{i}+\beta_{8} M S H A R E \_M I N_{i} \\
& +\beta_{9} R E P \_O F F_{i}{ }^{*} P R E V \_F I N E_{i}+\beta_{10} L_{P} 2002_{k}{ }^{*} R E P \_O F F_{i}+\beta_{11} L_{2} 2002_{k}{ }^{*} E E A_{i} \\
& \left.+\beta C_{k}^{\prime}\right)
\end{aligned}
$$

where

- $\quad Y_{i}$ is the dependent variable, $=1$ if the group is the chief witness, $=0$ otherwise;

- $\quad C_{k}^{\prime}$ is a vector of control variables

- $\quad i$ is the index for a group, and

- $\quad k$ is the index for a cartel.

Standard errors are clustered by cartels. We only include cartels that were convicted under either the 1996 or the 2002 leniency notice (due to the low number of observations for the 2006 revision). However, as the key structural reforms were implemented in 2002, we do not expect this restriction to be crucial for our main results. The results of our regressions are shown in Table 3.

6 For this reason, we have excluded ringleader status from the set of explanatory variables in our regression model. 
Table 3: Regression results (average marginal effects)

Cartel cases under 1996 and 2002 leniency programs

(1)

(2)

(3)

\begin{tabular}{|c|c|c|c|c|}
\hline & & CHIEF WITNESS & CHIEF WITNESS & CHIEF WITNESS \\
\hline RELATIVE DURATION & & $\begin{array}{l}0.00453 \\
(0.0680)\end{array}$ & $\begin{array}{l}-0.00963 \\
(0.0860)\end{array}$ & $\begin{array}{l}-0.0409 \\
(0.0818)\end{array}$ \\
\hline \multirow[t]{2}{*}{ REPEAT OFFENDER } & 0 & & base level & \\
\hline & 1 & $\begin{array}{c}-0.143 * * * \\
(0.0128)\end{array}$ & $\begin{array}{c}-0.171 * * * \\
(0.0166)\end{array}$ & $\begin{array}{c}-0.168 * * * \\
(0.0162)\end{array}$ \\
\hline BASIC FINE (in Mio. Euros) & & $\begin{array}{l}0.000265^{*} \\
(0.000152)\end{array}$ & $\begin{array}{l}0.000383 * * \\
(0.000192)\end{array}$ & $\begin{array}{c}0.000195 \\
(0.000182) \\
\end{array}$ \\
\hline \multirow[t]{2}{*}{$E E A$} & 0 & & base level & \\
\hline & 1 & $\begin{array}{l}-0.0834 \\
(0.0597)\end{array}$ & $\begin{array}{r}-0.142 \\
(0.133)\end{array}$ & $\begin{array}{c}-0.173 \\
(0.148)\end{array}$ \\
\hline NO. COUNTRIES & & $\begin{array}{l}0.073 * * * \\
(0.0271)\end{array}$ & $\begin{array}{l}0.115^{* * *} \\
(0.0360)\end{array}$ & $\begin{array}{l}0.109^{* * *} \\
(0.0356)\end{array}$ \\
\hline NO. FIRMS & & $(0.0231)$ & $\begin{array}{l}-0.0567^{*} \\
(0.0318)\end{array}$ & $\begin{array}{l}-0.0528^{*} \\
(0.0297)\end{array}$ \\
\hline REP. OFF. ${ }^{P} P R E V$. FINE & & $\begin{array}{l}0.00208^{* * *} \\
(0.000761)\end{array}$ & $\begin{array}{c}0.00154^{*} \\
(0.000923) \\
\end{array}$ & $\begin{array}{c}0.00148 \\
(0.000916)\end{array}$ \\
\hline \multirow[t]{2}{*}{ LP2002*REP.OFF. } & 0 & & base level & \\
\hline & 1 & $\begin{array}{l}0.837 * * * \\
(0.0142)\end{array}$ & $\begin{array}{l}0.816^{* * *} \\
(0.0167)\end{array}$ & $\begin{array}{l}0.812 * * * \\
(0.0175)\end{array}$ \\
\hline \multirow[t]{2}{*}{ LP2002*EEA } & 0 & & base level & \\
\hline & 1 & $\begin{array}{r}0.137 * \\
-(0.0834)\end{array}$ & $\begin{array}{c}0.231 * * \\
(0.102)\end{array}$ & $\begin{array}{l}0.219 * * \\
(0.105)\end{array}$ \\
\hline \multirow[t]{2}{*}{ MARKET SHARE MAX } & 0 & & & base level \\
\hline & $\begin{array}{c}1 \\
--\end{array}$ & & & $\begin{array}{c}0.131^{*} \\
(0.0713)\end{array}$ \\
\hline \multirow[t]{2}{*}{ MARKET SHARE MIN } & 0 & & & base level \\
\hline & 1 & & & $\begin{array}{l}-0.0488 \\
(0.0435) \\
\end{array}$ \\
\hline$N$ & & 405 & 252 & 252 \\
\hline pseudo $R^{2}$ & & 0.135 & 0.164 & 0.208 \\
\hline$B I C$ & & 315.9 & 233.4 & 236.6 \\
\hline$\%$ correctly classified & & 89.88 & 88.1 & 87.7 \\
\hline
\end{tabular}

Clustered standard errors in parentheses; ${ }^{*} p<0.1,{ }^{* *} p<0.05,{ }^{* * *} p<0.01$; Cartel control variables included but not reported.

Table 3 displays the average marginal effects of all variables on group level as well as the average marginal effects of the interaction terms. Cartel control variables are included but not reported. For categorical variables, the average marginal effect is the effect of a discrete change in the independent variable from the base level. For continuous variables, the average marginal effect is the effect on the dependent variable due to an increase in the independent variable by one.

Our main results are presented in regression (1). In hypothesis 1, we expected the probability of becoming the chief witness to increase with a cartel member's individual duration of cartel participation. Interestingly, although the RELATIVE DURATION variable partly shows the expected positive sign, the coefficient is found to be insignificant. This 
finding therefore somehow contradicts with our descriptive evidence that showed a clearly higher average duration of cartel participation for the group of chief witnesses.

As part of hypothesis 2, we expected repeat offenders to be more likely to become the chief witness compared to first offenders. We further expected that the probability is even higher under the revised 2002 leniency program. As shown in Table 3, we find contradictory (highly significant) evidence that being a repeat offender decreases the probability to become the chief witness (by about 14 percent). Interestingly, the decrease is getting smaller for increasing fines paid for infringements in previous cartel cases (as indicated by the REP.OFF. * PREV. FINE interaction term). Furthermore, the positive (and highly significant) interaction term between the dummy for the 2002 LP and the dummy for repeat offender is found to be larger than the marginal effect of the repeat offender variable itself. This finding allows the conclusion that while under the 1996 LP a change from single offender to repeat offender had a negative impact on becoming the chief witness, this effect is reversed under the $2002 \mathrm{LP}$. In other words, our empirical results support the conclusion that the 2002 revision of the LP substantially changed the role of repeat offenders (eventually confirming our hypothesis that repeat offenders are more likely to become chief witnesses).

Third, our results reported in Table 3 show that an increase in the basic fine leads to the expected positive change in the outcome variable (hypothesis 3). An increase in the basic fine of one million Euro leads to an average increase in the probability to become the chief witness of 0.03 percent.

Fourth, our hypothesis 4 stating that firms located in the EEA make better use of the LP is rejected as the coefficient of the EEA variable turns out to be negative and insignificant. Under the 2002 LP, however, a firm located in the EEA is more likely to become the chief witness. The coefficient of the interaction term LP2002*EEA is significant and indicates a positive change of around $14 \%$. This finding partly supports our hypothesis in so far as we conjectured that the revised LP reinforces the effect of firm location in the EEA.

Fifth, we find clear support for our hypothesis 5 assuming that the probability of being the chief witness increases with the number of countries within one group. As revealed by our empirical analysis, an increase of one more country increases the probability on average by about 7.3 percent.

Sixth, we do not find support for our hypothesis 6 stating that the probability of being the chief witness increases with the number of firms that form one group, as the corresponding coefficient is not significantly different from 0 .

Last but not least, regression (3) is similar to regression (1), however, includes two 
additional regressors in the form of two dummy variables that indicate whether the group combines the highest market share within the cartel in the relevant market or the lowest, respectively (referring to the remaining hypothesis 7). As this information was unavailable for roughly 38 percent of the groups, we not only ran the respective regression with the smaller sample but also replicated regression (1) to check whether the smaller sample is still representative for the total sample (see column (2) in Table 3). If the smaller sample is a representative extract, we would expect to observe no major differences regarding the significance of results. Referring to Table 3, we find a weakly significant positive effect for the group with the highest market share within the cartel thereby supporting hypothesis 7 defined above. In addition, the replication of regression (1) with the smaller sample in regression (2) reveals that the latter shows no substantial differences in the significance of results thereby confirming the representativeness of the smaller sample. ${ }^{7}$

\subsection{Discussion of key results}

Recapitulating our empirical results, on the one hand, we find evidence consistent with the hypotheses that the probability of a firm becoming the chief witness increases with its character as repeat offender, the size of the expected basic fine, the number of countries active in one group as well as the size of the firm's share in the cartelized market. On the other hand, we do not find empirical support for the expected relationships between the probability to become the chief witness and the duration of individual cartel participation, the location of undertakings within the EEA and the number of firms within a group.

Turning from these technical results to an economic interpretation, we can, first, say that the reform of the EC LP in 2002 did have a significantly positive effect on the incentives to self-report. In particular, we found evidence consistent with the hypothesis that the 2002 revision of the LP substantially changed especially the incentives of repeat offenders and firms located in the EEA to self-report. While repeat offenders were less inclined to report under the 1996 rules, the revision led to a turnaround making it more likely for a repeat offender to report. Although this finding might partly be driven by an uneven distribution of repeat offenders over time in our data set, it still supports the conclusion that the 2002 reform increased the effectiveness of the leniency program. This finding therefore suggests that future revisions of the LP should foster the incentives of repeat offenders to self-report, for example, by increasing the (expected) fines imposed on such firms.

7 Precisely, all significant variables in column (1) are also significant in column (2). However, the estimation results of the smaller sample additionally show a significantly negative impact of the variable NO. FIRMS on the probability of becoming the chief witness. 
Second, our finding that increases in the basic fine level leads to corresponding increases in the probability to self-report supports the empirical results of earlier empirical papers. Although on the surface, this result suggests further increases in the (expected) fine levels, the large literature on 'optimal deterrence' and 'optimal fines' argues that fines can be 'inefficiently high’ (e.g., as they might disencourage procompetitive (cooperative) actions or lead to substantial (cost-intensive) investments in hiding the respective infringements). Furthermore, the recent increase in the significance of private enforcement in the EU and the corresponding possibility of harmed customers of former cartelists to sue for damages factually increases the deterrence effect of competition law thereby raising the question whether current (public) fine levels are still sub-optimally low (see, e.g., Connor 2006, Veljanovski 2007 or Smuda 2014).

Third, our empirical finding that an increased degree of multinationality increases the probability to become the chief witness suggests that international cartel enforcement activities can be considered successful in the sense that, e.g., reputational spillover effects on sales after being detected as anti-cartel law infringer are considered as substantial additional cost of cartelization. Furthermore, the results also suggest that cartels are more difficult to stabilize with an increasing number of firms based in different countries. This finding also suggests that extensions of the scope of international cooperation among competition authorities increase the likelihood that one cartel member decides to report its involvement in the infringement.

Fourth, our finding that the size of cartel market share positively influences the decision to self-report might be used by the competition authority (or alternatively law makers) to increase the (expected) base fine for cartel members with high market shares thereby increasing pressure on them to self-report or alternatively to deter the participation in cartel agreements ex ante. Although current fines are already related to turnover and therefore market shares, an introduction of an additional multiplier could certainly strengthen the observed effect.

Complementary to the discussion of implications of our empirical results for competition policy, it cannot be ignored that they can also be helpful for cartels in the design and monitoring of their agreements. In other words, it can be expected that our predicted determinants affect cartel formation (or alternatively cause changes in cartel agreements), i.e. the observed effects may change over time as firms learn to operate in the new environment. For example, as our results suggest that both repeat offenders and cartel members with high market shares have a higher probability to self-report, the cartel might consider either 
excluding the respective firms from the cartel or at least to closely monitor their respective activities (and/or envisage special forms of punishment in case of deviation). Furthermore, the finding that multinational undertakings on average decide earlier to run to the enforcer's door generally suggests either minimizing the number of countries involved in a cartel agreement or (alternatively) to increase monitoring efforts to secure a cartel-friendly behavior of multinational cartel members. ${ }^{8}$ Last but not least, our results suggest that every cartel is well advised to closely monitor policy changes. As an increase in the basic fine also increases the probability to self-report, policy changes that factually lead to such (expected) fine increases are not unlikely to alter the cost-benefit ratio of cartel members in a way that reporting becomes the preferred option. Again, a cartel has to implement increased monitoring (and/or punishment) efforts in order to avoid a corresponding breakdown of the cartel.

In addition to the discussion of policy (and business) implications of our empirical results, it is important to conclude this section with the identification of several empirical challenges. First, although we controlled for a variety of characteristics that might affect the internal stability of cartels (and consequently the incentives to self-report), we were unable to include several potentially relevant additional controls such as general market conditions, business cycles or further characteristics of internal cartel structures.

Second, our selection of firm- or group-characteristics could also be extended, first and foremost by measures of financial performance (e.g., firm profitability or the ability to meet short-run obligations) as it is reasonable to assume that firms operating under financial pressures are more likely to self-report (thereby avoiding heavy fines) compared to financially healthy firms. Additionally, more accurate measures of firm size (such as turnover, number of employees, or ownership structure) would certainly enrich our model. Unfortunately, for both sets of variables, our efforts to receive the respective data (for the majority of groups or firms in our data set) were unsuccessful.

Third, future research could focus on a more precise capturing of the temporal structure of the leniency process in general and the exact timing of leniency applications and cartel investigations in particular (as both are likely to influence the incentives to self-report). The study by Gärtner and Zhou (2012) already follows this basic idea and therefore provides a useful basis for a comparable study with firm- or group-level data.

Fourth, the fact that a significant number of cartels in our data set were first detected by the US Department of Justice (DOJ) - and not by the EC - suggests that the decision to selfreport to the EC should be considered as 'automatic' rather than based on a detailed

8 Excluding big and international firms would, however, lower cartel stability (or impede cartel formation). 
comparison of the respective costs and benefits of self-reporting. As a consequence, our study on the determinants of self-reporting in the EU would certainly profit from a comparable exercise (at least) for the United States. Such a cross-country study would especially allow investigating the effects of different LP designs on the probability to self-report thereby deriving more general policy conclusions.

Last but not least, it is important to remind that our data set only consists of cartels that were convicted by the EC and therefore by definition excludes both stable cartels and cartels that collapsed but were not reported to the EC. As a consequence, our empirical approach is unable to study the internal dynamics of all cartels but can only address which member brings down a cartel in cartels that have failed and that have been convicted by the EC. Although it would of course be desirable to learn more on the behaviour of stable cartels, the fact that they are usually kept in secrecy suggest that only case studies of single agreements rather than data sets consisting of detailed information on many stable cartels could be an appealing focus of future research.

\section{Conclusion}

Over the last one and a half decades, leniency programs (LPs) have become a key tool to disclose illegal cartel agreements in many jurisdictions around the world. By offering fine reductions or even full amnesty from fines, competition authorities provide incentives to firms to come forward with information that is (potentially) sufficient to prove the existence of a cartel. In the European Union, the Commission introduced a leniency program in 1996 followed by two revisions in 2002 and 2006.

Given this increased importance of leniency programs in the fight against cartels, the question after the determinants of such self-reporting by cartel members immediately suggests itself. By identifying the respective key drivers, competition authorities would be able to adapt both the design of the leniency program and the fining guidelines accordingly thereby promoting the incentives of 'borderline' cartel members to come forward and report the cartel. Reaching such a further increase in the number of self-reporting firms would then directly translate into a corresponding increase in the positive contribution of cartel enforcement to (net) social welfare - basically through an earlier termination of existing cartels but also because a revised leniency program is likely to further increase the costs of firms to agree on new (and stable) cartel agreements.

Against this background, we have empirically investigated the determinants of selfreporting under the European corporate leniency program. Applying a data set consisting of 
442 firm groups that participated in 76 cartels decided by the European Commission between 2000 and 2011, we found that the probability of a firm becoming the chief witness increases with its character as repeat offender, the size of the expected basic fine, the number of countries active in one group as well as the size of the group's share in the cartelized market.

Although our empirical results might also provide hints for cartels on how to improve the stability of their agreements, we predominantly believe that they have important implications for an effective prosecution of anti-cartel law infringers. In addition to the general conclusion that an increase in fines leads to an increase in the incentive to self-report, our empirical analysis also supports policy reforms which aim at improving the respective self-reporting incentives for both repeat offenders and cartel firms with high market shares. Furthermore, an extension of international cooperation among competition authorities is likely to further increase the effectiveness of the EC leniency program through a promotion of the incentives of cartel members to self-report their involvement in an illegal conspiracy.

\section{References}

Abrantes-Metz, R., J. Connor and A. Metz (2012), The Determinants of Cartel Duration, Unpublished Working Paper, Purdue University, West Lafayette.

Brenner, S. (2009), An Empirical Study of the European Corporate Leniency Program, International Journal of Industrial Organization, 27, 639-645.

Brenner, S. (2011), Self-Disclosure at International Cartels, Journal of International Business Studies, 42, 221-224.

Buccirossi P. and G. Spagnolo (2005), Leniency Policies and Illegal Transactions, Journal of Public Economics, 90, 1281-1297.

Connor, J. (2006), Optimal Deterrence and Private International Cartels, Working Paper, Purdue University, West Lafayette.

De, O. (2010), Analysis of Cartel Duration: Evidence from EC Prosecuted Cartels, International Journal of the Economics of Business, 17, 33-65.

European Commission (1996), Commission Notice on the Non-Imposition or Reduction of Fines in Cartel Cases, Official Journal of the European Commission, C 207, 4-6.

European Commission (1998), Guidelines on the Method of Setting Fines, Official Journal of the European Commission, C 9, 3-5.

European Commission (2002), Commission Notice on Immunity from Fines and Reduction of Fines in Cartel Cases, Official Journal of the European Commission, C 45, 3-5. 
European Commission (2006), Commission Notice on Immunity from Fines and Reduction of Fines in Cartel Cases, Official Journal of the European Commission, C 298, 17-22.

European Commission (2006), Guidelines on the Method of Setting Fines, Official Journal of the European Commission, C 210, 2-5.

Ellis C. and W. Wilson (2001), What Doesn't Kill us Makes us Stronger: An Analysis of Corporate Leniency Policy, Working Paper.

Gärtner D. and J. Zhou (2012), Delays in Leniency Application: Is There Really a Race to the Enforcer's Door?, TILEC Discussion Paper, No. 2012-044.

Green, E., R. Porter (1984), Noncooperative Collusion under Imperfect Price Information, Econometrica 52, 87-100.

Haltiwanger, J., J. Harrington (1991), The Impact of Cyclical Demand Movements on Collusive Behavior, RAND Journal of Economics 22, 89-106.

Harrington, J. (2013), Corporate Leniency Programs when Firms have Private Information: The Push of Prosecution and the Pull of Pre-emption, Journal of Industrial Economics, 61, $1-27$.

Harrington J. (2008), Optimal Corporate Leniency Programs, Journal of Industrial Economics, 56, 215-246.

Levenstein, M. and V. Suslow, What Determines Cartel Success?, Journal of Economic Literature, 44, 43-95.

Marvao, C. (2010), The EU Leniency Programme and the Factors Affecting Fine Reductions, Working Paper.

Marvao, C. (2013), Heterogeneity of Penalties and Private Information, Working Paper.

Motta, M. (2004), Competition Policy, Cambridge.

Motta M. and M. Polo (2003), Leniency Programs and Cartel Prosecution, International Journal of Industrial Organization, 21, 347-379.

Motchenkova E. and R. van der Laan (2005), Strictness of Leniency Programs and Cartels of Asymmetric Firms, CentER Discussion Paper, Tilburg University, No. 2005-74.

Rotemberg, J., G. Saloner (1986), A Supergame-Theoretic Model of Business Cycle and Price Wars during Booms, American Economic Review 76, 390-407.

Smuda, F. (2014), Cartel Overcharges and the Deterrent Effect of EU Competition Law, Journal of Competition Law and Economics 10, 63-86.

Spagnolo G. (2005), Divide et Impera: Optimal Leniency Programs, CEPR Discussion Paper, No. 4840. 
Stephan, A. (2008), An Empirical Assessment of the European Leniency Notice, Journal of Competition Law \& Economics, 5, 537-561.

Veljanovski, C. (2011), Deterrence, Recidivism, and European Cartel Fines, Journal of Competition Law \& Economics, 7, 871-915.

Veljanovski, C. (2007), Cartel Fines in Europe: Law, Practice and Deterrence, World Competition 30, 65-86.

Zhou J. (2012), Evaluating Leniency with Missing Information on Undetected Cartels: Exploring Time-Varying Policy Impacts on Cartel Duration, TILEC Discussion Paper, No. 353. 